\title{
Governmental Cloud - Part of Cloud Computing
}

\author{
Cristian IVĂNUȘ ${ }^{1}$, Ştefan IOVAN ${ }^{2}$ \\ ${ }^{1}$ The Bucharest University of Economic Studies, \\ ${ }^{2}$ Informatica Feroviară SA, Bucharest \\ cristian.ivanus@neurosoft.ro stefan.iovan@infofer.ro
}

Large IT (Information Technology) companies propose cloud government's (G-Cloud) development model through investment from the private sector, which will facilitate the access of users from public sector to the new generation IT services. Through the G-Cloud private operators that operate governmental cloud infrastructure by adding specific SaaS (Software as a Service) functionalities, proposed model by big companies, supports public institutions in optimizing costs and increased operational efficiency, bringing tangible benefits in relation with citizens and thus with the whole society. These optimizations are achieved by moving the initial investment to the private sector, through type subscription model cost by eliminating dependency on human factors (technical) and by providing a low cost [1]. This paper aims to bring to the attention of specialists, some aspects of Governmental Cloud from the European Union (EU) countries to be understood and implemented in Romania.

Keywords: Cloud Computing, Governmental Cloud, Big Data Analytics

$\mathbf{1}^{1}$ Introduction

Government Cloud is a concept already introduced in other European countries such as Great Britain (under the name of G-Cloud), providing quality public services and much more easily accessible to citizens. Large IT companies bring on the Romanian market the technology and the expertise to provide innovative solutions for the public cloud sector.

Creating an integrated and unified government cloud market, assumes the emergence of private operators to manage the access to cloud solutions and which operate in an efficient infrastructure of public institutions. Through collaboration, major IT companies intend to facilitate the access and the use of integrated IT solutions at the national level, in cloud, with minimal investment from the state budget [2].

2 Cloud computing in the European Union 2.1 A short history of cloud computing in the $\mathrm{EU}$

In September 2012, the European Commission (EC) adopted a strategy for "Unlocking the potential of cloud computing in Europe" [3]. The strategy aims to encourage the use of cloud computing in all sectors of the EU economy and the group of experts is a key element in this strategy and the Commission's efforts to encourage further development of the unique digital market.

The strategy is based on other legislative initiatives, such as EU reform of data protection [4] and the optional European legislation proposal in sales area [5]. Expert Group helps the Commission to examine how to improve the legal framework for cloud computing contracts for consumers and SME's [6], in order to strengthen the confidence of consumers and SMEs on the usage of cloud computing contracts.

"Cloud computing" concept describes the procedure for storing data (such as text files, pictures and videos) and the use of software on remote computers accessed by users, through the internet, using any device they want. This method is faster, cheaper, and more flexible and potentially more secured than local IT solutions.

Many services such as Facebook, Spotify and web-based email, use cloud computing technologies, but the real economic benefits are obtained only when these cloud solutions are widely adopted by companies and public sector organizations. 


\subsection{EC Strategy in cloud computing} domain

The Commission's strategy on cloud computing includes three key actions, one of these aiming to identify secure and fair contractual terms and conditions for cloud computing contracts. The existence of standard contractual clauses can contribute to the facilitation of contractual agreements between service providers and cloud consumers or small businesses. These can also facilitate the application of the EU rules data protection, to the extent that respective terms are relevant to the cloud computing contracts. European Commission's proposals for reforming the data protection, which received an overwhelming majority of votes in the European Parliament [4], will introduce also a framework that will contribute and encourage the development of cloud computing services. A rapid adoption of reform proposals on data protection will support the development of the unique digital market and will guarantee that both consumers and SMEs will take full benefits from the economic growth in the digital services and cloud computing services. By European Community proposal for a common European sales legislation, the Commission has already started to work on legal framework improvements for cloud computing contracts [5]. Thus, the common European legislation will establish an optional legislation on sales, applicable throughout the EU that will include fair and balanced rules that consumers and SMEs will be able to use when buying digital products such as music or software, downloading them from the cloud.

For matters not related to the common European sales legislation, the expert group will carry out specific complementary activities to ensure that other contractual issues relevant to cloud computing services may be included in the scope of those rules, through an similar optional instrument.

\subsection{Cloud Computing legislation in the EU} The European Commission has established a group of experts to develop safe and fair terms for cloud computing contracts at the European level, based on an optional instrument. EC objective is to identify best practices dedicated to consumers and small businesses, which often, due to lack of clarity of the respective contracts, are reluctant to purchase cloud computing services.

The creation of the expert group is part of the Commission's efforts to increase trust in cloud computing services and to maximize their potential, to stimulate economic productivity in Europe. This action is one of the main actions undertaken by the EC in the cloud computing strategy adopted in 2012 [7, 8].

The group has also the role of addressing issues related to cloud computing out of the scope of common European sales legislation, which is now under the negotiation [5].

The cloud computing expert group includes representatives of the cloud computing service providers, consumers and SME's (Small and Medium Enterprises), academics and legal professionals. The first group meeting will report on its work by the end of 2014.

Received contributions will form the basis of a policy document which will launch a broad public consultation about the options for future action on contracts for the cloud computing for consumers and SMEs in Europe. At the European Council, EU leaders have highlighted the need of measures that will contribute to the creation of a single market for cloud computing services.

The Commission has already taken measures with regard to this issue. From the full exploitation of the cloud computing benefits, it could be generated 2.5 million new jobs in Europe, and by 2020 the EU's gross domestic product would increase by about $1 \%$ per year. Experts must provide the consumers and small and medium enterprises a balanced set of contractual clauses, so that they can use cloud computing services with more confidence. Trust is an advantage - people should be able to have confidence that the services they are using are fair and reliable.

\section{Governmental cloud in Romania}

The initiative from Romania is aligned to the European Commission directives, which encourages the use of cloud computing 
technology in e-Government projects in order to generate savings in government budgets. Dedicated Romanian Government Cloud can be built on three main pillars:

- online access - the meeting point between public institutions and beneficiaries of the services offered by the romanian state;

- integration - include specific services of regional institutions and their common processes, from the accounting to infrastructure management;

- interopperability - facilitating the exchange of data and services between public institutions, even if they use different cloud solutions.

The new role of the G-Cloud private operator, becomes essential in the government cloud ecosystem. This will ensure and guarantee the management of cloud services to citizens through the public institutions and an integrated SLA (Service Level Agreement) of all these services [9]. For implementing this model it is required a joint efforts of major IT companies so that, together with the authorities from Romania, to develop public policies for defining the entire framework of cloud implementation as well as specific requirements for private G-Cloud operators.

For the implementation of this concept in Romania, it is necessary to develop a certification scheme for agreed public sector cloud service providers as well as the appropriate legal framework.

\subsection{Increased efficiency for public administration}

The creation of a market for government cloud has the potential to increase the level of technology in the public sector, covering IT needs at the central and local administration level, through a viable alternative to the currently used traditional solutions. Public administration will become a more transparent institution and efficient IT service provider to the citizen.

Government cloud solutions does not require public authorities investment in IT systems. The consumption of resources is based on a monthly subscription, and responsibility for the administration and maintenance of cloud infrastructure lies to the private operator. In this way, costs are predictable and the problems related to lack of specialized personnel in public institutions, dissapears.

Used in the public sector, cloud technology supports citizens, simplifying the procedures and facilitating the access to solutions that radically transform the experience related to the public administration.Thus, high quality services will be delivered quickly to citizens. Government Cloud means easy access to information for citizens, reduced errors from files, simplified interaction between users and the public institutions and, very often, considerable decrease of displacements and time spent at wicket desks.

Creating a framework for opening the market of public services of governmental cloud to private operators, becomes essential in an era governed by mobile technologies that simplify people's lives.

\subsection{Simplified collaboration simplified and improved efficiency}

Sharp has launched a new service dedicated to the European market: Cloud Portal Office. This allows users to share and store data, streamlines the workflow, helps companies to effectively collaborate and to increase their productivity. Cloud Portal Office provides access to information on an extended hardware platform, to devices both fixed and mobile. It is also a perfect solution for companies with a large network of offices and branches or those that have a large number of operators on the ground.

The portal was created to facilitate the sharing of information, to enable the access, upload, download, manage and secure manner printing files, new folders creation, cooperation and sharing of data on any computer, mobile device, multifunctional device or interactive Big Pad whiteboard. It facilitates the working process, allowing team members to securely access any information they need: immediate and wherever they are. It is a very useful service that supports companies in their daily work and in projects they implement, especially for those involving employees from different departments or 
offices or even different countries. Cloud Portal Office is extremely flexible; it can quickly and easily configure different units and can add access rights to a shared space in the cloud.

The portal enables the employer to increase or reduce staff involvement, which reduces operating costs of the company. Cost reduction can be determined also by providing immediate access to company resources in the cloud, without the need of costly investments in IT infrastructure. In this simple way, access to documents can be extended without the need for providing secure access to an FTP server or a VPN connection.

Cloud Portal Office offers storage solutions from the most trusted partners. The data are stored only on secure servers operated by Amazon Web Services and Fujitsu Cloud Services. These are protected by access control, screen protections and the latest encryption methods. In addition, all resources are stored in the European Union.

Cloud Portal Office is also available for those which will connect to the portal; company's IT staff controls the access to the resources. CPO (Chief Product Officer) allows the user to modify access rights, delete or add individual access and increase data storage space if needed - everything is done through a secured website.

\subsection{Romanian cloud offer for public entities} National Institute for Research in Informatics (ICI) launched, under a public event, a proposal to become a cloud computing services provider for government entities, companies and citizens. The proposal is based on the project "Cloud Infrastructure for Public Institutions" - ICIPRO, which is based on data center construction ICI for this purpose.

Data Center is a joint investment of over 77 million lei. About 13 million of this amount is the participation of the Institute from its own funds, the rest coming from the European Union, through the Structural Funds POSCCE.

ICI data center is represented by a specially designed building with a dedicated project built area of over 300 square meters, located in the premises of the institute. Once completed, probably in the year 2015, the project will be open to the public entities who want to use cloud computing services. At the first instance, this data center will be used even by ICI, which will move into the cloud domenii.ro area and the IT programs public library already managed inside the institute.

Through this project, Romania gives a clear message that it goes to the stage of "early adopter" in terms of cloud computing. From the point of view of the experts, the first beneficiaries of such a project will be county councils and local public administrations.

Current status of the project is the completion of construction of the data center, subject to receive the approval for connected to the public network power supply. There are no public information offered on IT infrastructure that will be installed in the data center.

\subsection{CloudSME - simulation in cloud SME's}

The development of a new business ideas or investing in new technologies and methods, constitutes a major challenge for companies. To simulate a process or a system or design a model using a simulation software means to pretest the behavior in order to match with the real system. Simulation will avoid uninspired investments, enabling companies to detect in advance weaknesses and errors in the workflow or products.

CloudSME is a European project [10], which has as main goal to bring small and medium companies closer to cloud computing. The project will develop a simulation platform into the cloud, which will allow SMEs mainly active in the fields of engineering and production, to use simulation technology as a service (SaaS, one-stop-shop, pay-per-use). Thus, they will not have to make massive investments in software licenses, related hardware and maintenance, but only will use the benefits of simulation to improve productivity.

Simulation software can significantly improve the position of these SMEs by reducing costs 
and delivering more efficient development, production, purchasing, logistics and financial processes. However, until now, the adoption of software simulation by SMEs was reduced due to the barriers such as hardware prices, the cost of licensing and technical expertise.

CloudSME develop a single platform, onestop-shop for software simulation based on cloud, which significantly reduces these barriers, allowing wider adoption of simulation software among SMEs in the engineering and production. Software providers can use simulation as a service platform as Platform-as-a-Service (PaaS), which allow them quickly create custom applications in the cloud for their customers mentioned SMEs - which will see the custom applications running as a Software-as-aService (SaaS) in the cloud.

To achieve a higher impact CloudSME simulation solution, project requires the participation of up to ten new SME beneficiaries enrolled in an EU Member State or FP7 associated country. These new beneficiaries must be

- an SME that has as main activity the engineering and production and requires simulation software to improve their effectiveness, and will use the simulation software supported by CloudSME or

- an consortium that integrates at least one SME software simulation provider and one or more SMEs working in the engineering and production that will use software simulation provider.

As new beneficiaries of CloudSME, simulation software vendors must adapt software simulation to the CloudSME platform, to implement it and help SMEs to create simulation applications on CloudSME platform using their software.

With regard to the SMEs in engineering and production, as new beneficiaries, they must:

- to define requirements for business activities that will be supported by simulation on the CloudSME platform,

- to contribute to the creation of simulation applications for supporting their work,

- to cooperate with technology and simulation software suppliers from the platform,

- to use the application in the current activity, and

- to provide feedback on improvements.

\section{5 e-SENS: Business Opportunities in the public sector}

A series of e-government services are already provided at national level. However, there are still many barriers found when government services are accessed transboundary; these obstacles are varying from the technological, legal, organizational to the semantic level.

e-SENS (European Simple Electronic Networked Services) is a project [11] funded by the European Union,with aims to develop interoperable technical solutions and online public services in the European Union and associated countries. The project focuses on fundamental technical modules such as eIdentity, e-Signature, e-Delivery and eDocuments.

After the first year of the project, it was created the foundation for the development of necessary ICT architecture (Information \& Communication Technology) and also were defined the piloting scenarios to simulate reallife cases.

The purpose of the pilot phase is to demonstrate the feasibility of implementing real ICT services between countries in Europe. e-SENS pilot applications will demonstrate that it is possible to obtain a perfect electronic communication with public administration within the European Union. Actual transactions between companies / citizens and public administrations based on generic pillars, will be available in a wide range of activity domains.

The pilot phase will demonstrate that developed technical solutions can be implemented across Europe, providing a unique opportunity for European citizens and businesses to achieve maximum benefits from a single digital market.

The solutions of the project are in line with European standards and regulations for crossborder electronic communication. Fundamental technical modules can be used for free by the IT sector for developing new 
services. In this way is is possible to obtain competitive advantage on the European market.

\section{Big data analytics in governmental cloud} While the economic organizations, scientific and government organizations accumulate unprecedented rates of data, relevant business data analysis available to each employee remains largely a dream. Business analysts and IT have access to a multitude of data, but ordinary workers still struggling to obtain and analyze information in a timely manner.

To allow all users to access the most relevant data, whenever and wherever they need it, software companies have launched cloud services that offers analytics solutions suite. Having embedded mobile phone capabilities, these services supports the speeding up of decision making process within the organization by reducing access limitations to users, offering secure access to comprehensive information and cost efficiency in the cloud.

These services that extend the power of essential information are based on data analysis and data visualization for users throughout the organization. It is based on already checked BI (Business Intelligence) technology, being optimized for cloud services and allowing users to combine data from different sources either from the cloud, or headquarters of the organization or from third-party applications, in order to quickly create interactive rich applications and analysis.

Because cloud offer is based on a subscription, customers can deploy these services immediately, for small groups, business departments or the entire organization without capital costs. Services include out-of-the-box capabilities, so customers can access and analyze data anytime and anywhere without any additional development effort.

IT organizations that develop government cloud can use these cloud services to deliver rich, personalized applications to their customers, developing new revenue streams. The offer also frees valuable IT resources, while allowing IT to maintain a security check on a company's information architecture.

Built on the platform of industry leaders (eg, Oracle Database Cloud) serviciiile of "Big Data Analytics" are based on a robust functionality and is used by millions of people worldwide.

\subsection{Rich and interactive experience}

"Big Data Analytics" services allow users at all technical levels to quickly and easily create analytic applications, having the following characteristics:

- Fast startup: The data import model supported by a wizard, users can build tests, or mixes BI applications without any programming skills or analysis.

- Ease of implementation: An interactive interface with guidance and integrated tutorials improve the productivity and implementation. Users who have previous knowledge about services in the cloud or cloud applications can use the services immediately without specialized training. Best practices in cloud industry are also included.

- Mobility: Having "on-the-go" analysis capabilities, it includes tactile and interactive features, without requiring additional development. In addition, services are equipped for offline usage, with an advanced security to manage access and visibility.

- Flexibility: For more customized options, for a better integration, users can get programming interfaces.

\subsection{Reduce administration efforts and maintain security}

With "Big Data Analytics" services, organizations can reduce costs and necessary resources to implement analytical applications, while maintaining a complete database administration.

Benefits:

- Scalability: The model based on cloud enables organizations to add new users and applications;

- Availability: The services provide high availability, while companies producing services optimize the speed by transfering the 
analysis of complex processes to the cloud.

- Security: Data and BI applications are part of the portfolio that meets the highest security standards in the industry and is fully owned and operated by the company, ensuring that no data will be transmitted to third parties.

- Simplicity: IT companies manage upgrade cycles and software patching, releasing more IT resources and provides immediate availability of the latest solution

- Elasticity: The service provides the power of the database (eg Oracle) and sophisticated BI skills for supporting current and future needs of business data analysis.

Information has the power to transform business - but only if they are in the hands of the right people at the right time. "Big Data Analytics" services, with embedded mobile capabilities, will speed up and improve decision-making process in companies and government organizations by reducing data access barriers for all users through a secure and wide access to information, using the simplicity and cost effective of the service cloud.

Snap-on Business Solutions is expected to achieve productivity growth in developing Oracle applications and to accelerate deployment times in environments with large volumes of data, due to the capabilities offered by Oracle BI Cloud Service, in order to quickly format and present the visual results by charts, graphs and reports.

Users must interact in some way directly with databases in order to achieve faster analysis results. "Big Data Analytics" BI services facilitate this by allowing loading and combining data from multiple sources much easier. Along with embedded mobile capabilities, "Big Data Analytics" services is a guarantee that it will provide employees with the analysis "however and wherever" they need it.

\section{Internet of things usage in the public sector}

Internet of Everything ( $I o E$ ) could generate an economic value to the public sector of 4.6 trillion dollars over the next 10 years, according to a study released by Cisco in
2014. This big amount of money will be obtained from the efficient management of resources, increase employee productivity, generating new revenue (without raising taxes) and the benefits for citizens [12].

IoE means connecting people, processes, data and things and added value resulting from the fact that anything can connect to the network. Transition to the ,Internet of Things”, increased mobility, the emergence of cloud computing and the increasing importance of "big data" are elements that helps to the development of IoE.

For example, the city of Barcelona [13] currently uses IoE solutions to provide new and improved experiences. Spanish Town is one of the first in Europe who developed "virtual services" for its citizens and using video and collaboration technologies to enable humans to interact remotely with the City Hall.

It is also one of the most connected and intelligent communities in the world that implemented IoE solutions in water management, smart parking, waste management, public transport, which helps the city to save money and to improve services provided to citizens.

At the level of municipalities, IoE can generate a value of 1.9 trillion dollars over the next 10 years. Cities can benefit by implementing "killer apps":

- Intelligent buildings could generate 100 billion dollars by reducing operational costs related to energy consumption by integrating heating, ventilation and air conditioning.

- Monitoring of gas consumption could generate 69 billion dollars by reducing costs and increasing accuracy of metering readings for people and utility providers.

- Smart Car parkings could generate 41 billion dollars by providing real-time visibility on the availability of parking in the city. Citizens can find and reserve the nearest available parking, traffic agents can easily identify irregularities, and the municipality may introduce a charging system based on demand.

- Water management could generate 39 billion dollars by connecting the water meter 
in the house on an IP network to provide information on usage.

- Traffic charging system could generate new revenue $\$ 18$ billion by implementing an automated system in crowded areas of the city, which would improve traffic conditions while increasing revenues.

As a growing percentage of the population migrate to urban centers, cities must become more flexible and responsive to citizens' needs by optimizing existing revenue. IoE transforms the way in which services are delivered to citizens and their interaction with the administration.

In addition to the benefits to cities, IoE has an impact on every level of administrationas shown by the analysis:

- State agencies can achieve revenues from IoE solutions in the amount of 682 billion dollars through their use in the management of bridges, transportation of prisoners, chronic disease management, education and fire service.

- Non-defense federal agencies could get 472 billion dollars using IoE solutions to improve disaster response, fleet management, cyber security and many other areas.

- Defense worldwide military forces can improve their missions efficiency through a connection and exchange secure information between soldiers, bases, vehicles and data from the theaters of war. Improved connections between global defense forces could generate a value of 1.5 trillion dollars and increase in a measurable way the safety of soldiers.

With a total of 350 million public employees globally, IoE applications that improve their productivity in state agencies, local and nondefense would generate considerable value. For example, remote working solutions could create a value of 125 billion dollars by reducing rental costs, printing and other costs. However, such solutions improve employee productivity and retention and provide new employment opportunities.

Public sector leaders are under the fantastic pressure to meet raising expectations of citizens with resources that constantly become smaller. IoE solutions can change the situation. Public sector leaders should act by identifying opportunities to implement IoE in their agencies and start to imagine what can be achieved in a world of Internet of Things.

Study [14] is added to another study conducted by Cisco in February 2013. According to this, private companies that adopt IoE solutions will record profits of about 14.4 trillion dollars over the next 10 years. The aggregate value generated by IoE will be 19 trillion dollars in the two sectors over the next 10 years.

\section{Conclusions}

In the final part of the work we will analyze IT solutions for public institutions in Romania in the European context and how much closer they are compatible with the government cloud. To improve the ICT infrastructure from public institutions in Romania $[15,16]$ in the interest of the citizen, we believe that following aspects must be considered:

- The current state of eGovernment projects at central level: Single Point Contact (PUC), Electronic System for Public Acquisitions (SEAP) National System Electronic Payment of taxes using credit card (SNEP) System Electronic Transport Award (Saeta) Electronic prescription Information System (SIPE), Integrated Information System (SIUI) etc. and the state of the projects at local level; - Projects and future measures to ensure interoperability, efficiency and effectiveness of existing and future infrastructure;

- Measures on the transition to the cloud computing and creating a governmental cloud;

- Creating the national framework of networks security and information systems, applicable to the state institutions and critical infrastructures;

- Implementation of measures for assessing the vulnerability and penetration tests for the cloud computing architectures and cloud monitoring services;

- Creating a national system for monitoring and combating cyber attacks by integrating public and private sector institutions systems; - Action and solutions to combat intrusion and cyber terrorism, both in the context of 
actual ICT infrastructure and in the context of IoT (Internet of Things - IoT).

These conclusions are oriented for supporting the development of information society in Romania for the benefit of the citizen and for the evolution of Romania toward the high level of EU countries [17]. At the same time, this work aims to develop the interest of the citizen for the information society, the society where we are living now, where ICT, software and hardware became a critical infrastructure of human society, without which it can not operate and perform in all spheres of activity.

\section{Acknowledgement}

This work was partially performed within the project POSDRU /159 /1.5/S/142115 entitled "Performance and excellence in doctoral and postdoctoral research in the field of economics in Romania", financed from the European Social Fund through the Sectorial Operational Programme Human Resources Development 2007 - 2013

\section{References}

[1] St. Iovan Folosirea tehnologiei "cloud computing" in sectorul public, ClujNapoca: Editura Presa Universitară Clujeană, Romania, Volumul: "INTELIGENŢĂ, TERITORII ŞI DEZVOLTARE UMANĂ", (Coordonatori: Mihai Pascaru, Lucian Marina, Călina Ana Buţiu), ISBN: 978973-595-707-0, pag. 193 - 204;

[2] Cr. Ivanus, and St. Iovan, Cloud Computing Technology Trends, TarguJiu: "Academica Brancusi" Publisher, Romania, Fiability \& Durability, Issue: Supplement No. 1/2014, (SYMECH 2014), pag. 264 - 269;

[3] Comisia Europeana, (2012), IP/12/1025, MEMO/12/713;

[4] Comisia Europeana, (2013), MEMO/13/923;

[5] Comisia Europeana, (2013), MEMO/13/792;

[6] * * *, http://cloudsme.eu/opencall (accessed in May 2014);

[7] Comisia Europeana, (2012), IP/12/1025;
[8] Comisia Europeana, (2012), MEMO/12/713;

[9] P.V. Ionescu, and St. Iovan, The Adoption of Cloud Computing at the Governmental Level and the Problem of Interoperability, Bucharest: Proc. of 13th European Conference (E_COMM_LINE 2012), Romania, ISBN: 978-973-1704-22-7;

[10] Comisia Europeana, (2013), IP/13/590;

[11] FUJITSU Cloud Initiative, http://www.fujitsu.com/fts/about/resource s/news/press-releases/2013/FTS130711-

Fujitsu-Declares-Comprehensive-Global--Trusted.html (accessed in June 2014);

[12] Cr. Ivanus and St. Iovan, "Internet of Things" - A new Technological Evolution, Targu Jiu: "Academica Brancusi" Publisher, Annals of the "Constantin Brancusi" University, Engineering Series, Issue 4/2013, (CONFERENG 2013), ISSN: 1842 4856, pag. 165 - 170;

[13] Cisco, Barcelona Embraces IoE to Create a Smart City, http://www.youtube.com/watch?v=TCbv $\mathrm{xb} 5 \mathrm{t} 5 \_8 \&$ feature=youtu.be (accessed in June 2014)

[14] Cisco, Internet of Everything: O oportunitate de 4,6 mii de miliarde de dolari pentru sectorul public, http://www.internetofeverything.com (accessed in june 2014)

[15] http://www.agora.ro/conferinta/solu-iiinformatice-pentru-institu-iile-publicedin-romania-contextul-european (accessed in July 2014)

[16] St. Iovan and Gh.I. Daian, Impact of Cloud Computing on Electronic Government, Targu-Jiu: "Academica Brancusi" Publisher, Romania, Fiability \& Durability, Issue: Supplement No. 1/2013, (SYMECH 2013), pag. 71 - 77;

[17] St. Iovan, The Cloud for Public Services, Bucharest: Proc. of 15th European Conference (E_COMM_LINE 2014), Romania, ISSN: 2392-7240, ISSN-L: 2066-6829; 


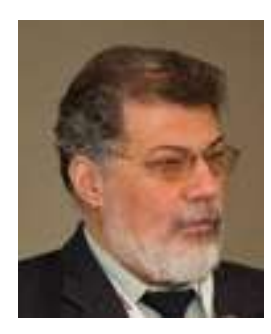

Cristian IVĂNUȘ has graduated the Faculty of Electronics and Telecommunications of the University Politehnica of Bucharest in 1985. He also finished the Master's degree in Information Technology at the University of Liverpool in 2005. Starting with 2013, Cristian is a $\mathrm{PhD}$ candidate at Bucharest University of Economic Studies in the field of Economic Informatics. At the present, he works as independent business and IT consultant for different companies and provide professional trainings in BPM.

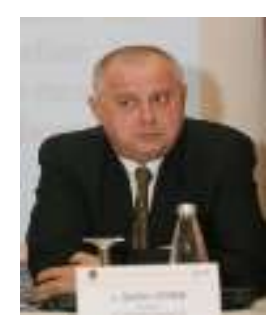

Ştefan IOVAN has graduated the Faculty of Mathematics of the University of Timisoara in 1979. He is PhD in Mathematics of the University of Timisoara from 2007. Stefan is the author or coauthor of more than 175 works published and/or presented at national and international conferences. At the present, he works as IT Consultant/Counselor at Informatica Feroviara SA and is Associated Professor at the West University of Timișoara. 